\title{
TREATMENT OF OSTEOID OSTEOMA IN THE VERTEBRAL BODY OF THE LUMBAR SPINE BY RADIOFREQUENCY ABLATION
}

\author{
Alexandre Fogaça Cristante, Tarcisio Barros Filho, Reginaldo Perilo de Oliveira, Almir F Barbarini, William GJ Teixeira
}

\section{INTRODUCTION}

Osteoid osteoma is a rare bone tumor initially described by Jaffe in $1935 .{ }^{1}$ It is characterized as a bone-producing tumor that is most frequently observed in the lower extremities of children or young adults (11-22 years). Osteoid osteoma is differentiated from osteoblastoma according to size. Osteoid osteoma is smaller than 1.5 centimeters in diameter. $^{2}$

In approximately $10 \%$ to $25 \%$ of the cases, ${ }^{3-8}$ the tumor is observed in the vertebral column with a predilection for posterior elements of the vertebrae. ${ }^{9-11}$ In only $10 \%$ of the cases in which the spine is affected ${ }^{12}$ is it found in the vertebral body, but involvement of the spine is more common in the lumbar vertebrae. ${ }^{12,13}$ Here the disease is characterized by localized pain in the affected vertebra, ${ }^{14,15}$ and possibly by radiating pain similar to a disc hernia, ${ }^{9,16}$ although without other findings in the physical and neurological evaluation. ${ }^{17}$ The pain is generally worse during the night and improves with the use of non-hormonal anti-inflammatory drugs. ${ }^{18}$

Scoliosis secondary to pain and muscular spasms ${ }^{19}$ is a common finding in affected adolescents (63\% to 70\%). If treatment is delayed, scoliosis may become a complication since the curve may become structured through asymmetric inhibition of the growth of the vertebral epiphysis. ${ }^{13,17,20,21}$ The tumor is generally located at the apex of the deformity. ${ }^{18,19}$ When the fourth or fifth lumbar vertebra is involved, it is generally associated with pelvic obliquity. ${ }^{18}$

The tumor niche, even when small, can generally be observed by means of scintigraphy with technetium. ${ }^{22}$ It is possible to identify the lesion on tomographic sections of thickness less than 1.5 centimeters and magnetic resonance images (MRI). Osteoid osteoma is better seen on MRI because of its high signal in the bone around the lesion in

Instituto de Ortopedia e Traumatologia, Hospital das Clínicas, Faculdade de Medicina, Universidade de São Paulo, Brazil

Email: aacristante@uol.com.br sections with $\mathrm{T} 2$ weighting, thus demonstrating local edema. $^{22}$

\section{CASE REPORT}

A 44-year-old female patient sought orthopedic attendance because of constant lumbar pain that had lasted for two years with progressive worsening. She reported that the pain was more intense at night, but did not worsen with movement or any pain crises during the day. Her pain did not radiate to the lower limbs or other regions. There was no history of trauma, fever, weight loss, or sphincter alterations. She had previously undergone treatment with non-hormonal anti-inflammatory drugs, with improvement only while she was using the medications. On physical evaluation, she had pain on palpation of the fourth lumbar vertebra, without deformity. Neurological and vascular examinations did not present alterations.

Radiography of the lumbar spine did not reveal abnormalities. Scintigraphy using $\mathrm{Tc}^{99 \mathrm{~m}}$ demonstrated increased uptake on the left side of the vertebral body of the fourth vertebra (figure 1). Computed tomography of the lumbar spine revealed an area of hypoattenuation surrounded by an area of hyperattenuation (bone sclerosis), suggestive of an osteogenic tumor (figures 2 and 3). Complementary exami-

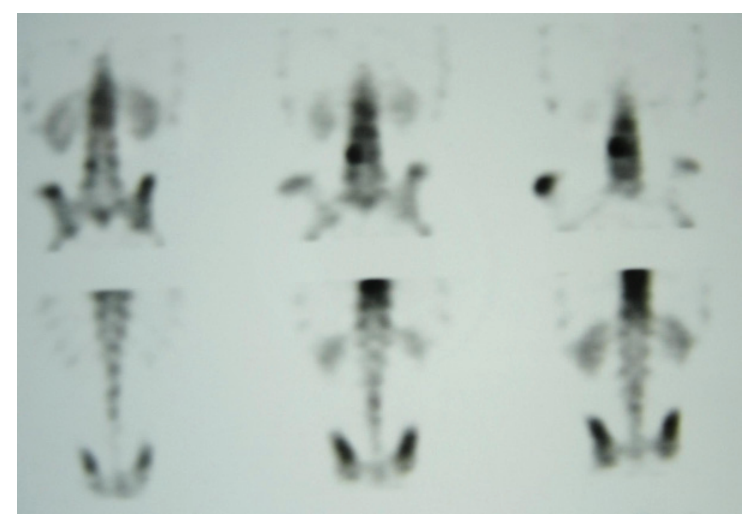

Figure 1 - Scintigraphy with the use of Tc $99 \mathrm{~m}$ demonstrated increased uptake on the left side of the vertebral body of the fourth lumbar vertebra. 


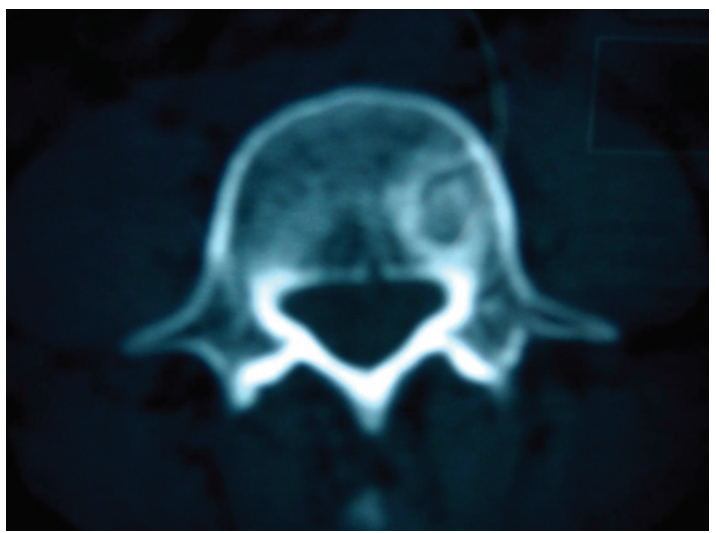

Figure 2 - Computed tomography demonstrating an area of hypoattenuation surrounded by an area of hyperattenuation (bone sclerosis).

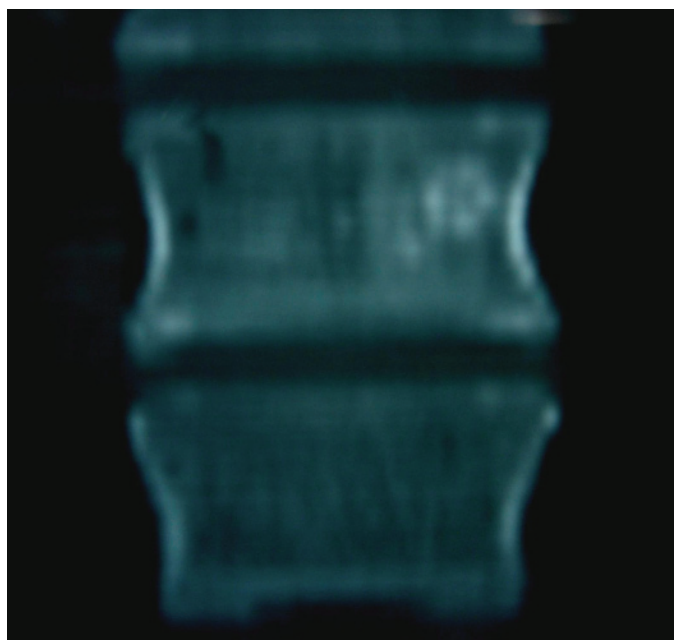

Figure 3 - Tomographic reconstruction demonstrating the tumor niche and adjacent bone sclerosis.

nation using MRI demonstrated a signal alteration of $1 \mathrm{~cm}$ diameter in the vertebral body of the fourth lumbar vertebra, close to the base of the left pedicle, surrounded by an area of signal compatible with bone edema (figures 4 and 5). The anamnesis data, physical evaluation, and complementary examinations suggested the presence of osteoid osteoma in the vertical body of the fourth lumbar vertebra.

A tomography-guided biopsy was performed, and material was collected for cultures, pathological studies in paraffin, and fast freezing (in print). Pathological study of frozen sections ruled out the presence of neoplastic cells. At the same time, minimally invasive destruction of the tumor was performed through a pedicullar approach, via an Arthrocare ${ }^{\circledR}$ radiofrequency probe set at $80^{\circ}$. The correct positioning of the probe was confirmed with computed tomography (figure 6). The histopathological examination of paraffin sections confirmed the diagnosis of osteoid osteoma (figure 7). There was no bacterial growth in the cultures collected.

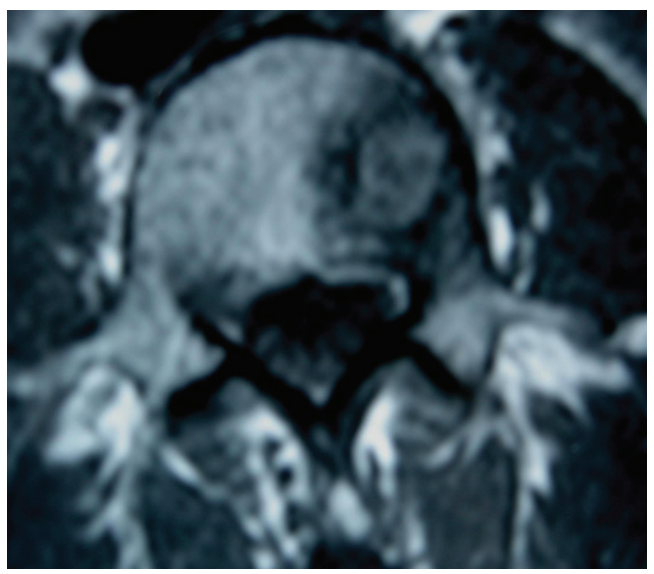

Figure 4 - Magnetic resonance showing an axial section through the fourth lumbar vertebra in a $\mathrm{T} 1$ sequence, demonstrating alteration in the vertebral body at the base of the left pedicle.

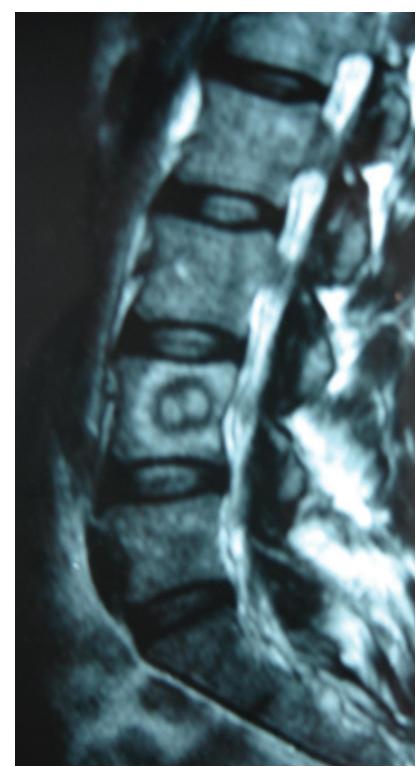

Figure 5 - Magnetic resonance showing a sagittal section through the lumbar column in a 2 sequence, demonstrating the tumor niche and the sclerosis halo.

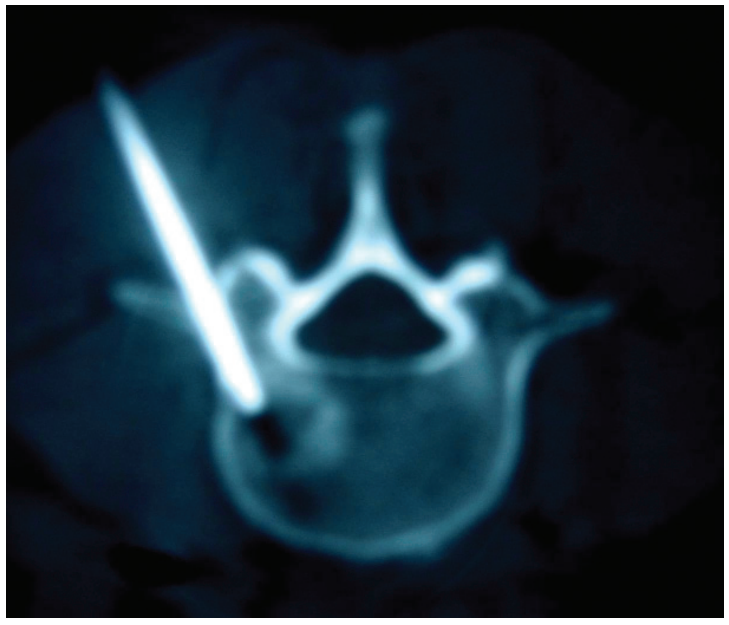

Figure 6 - Tomographic image of the minimally invasive transpedicular procedure in the fourth lumbar vertebra. 


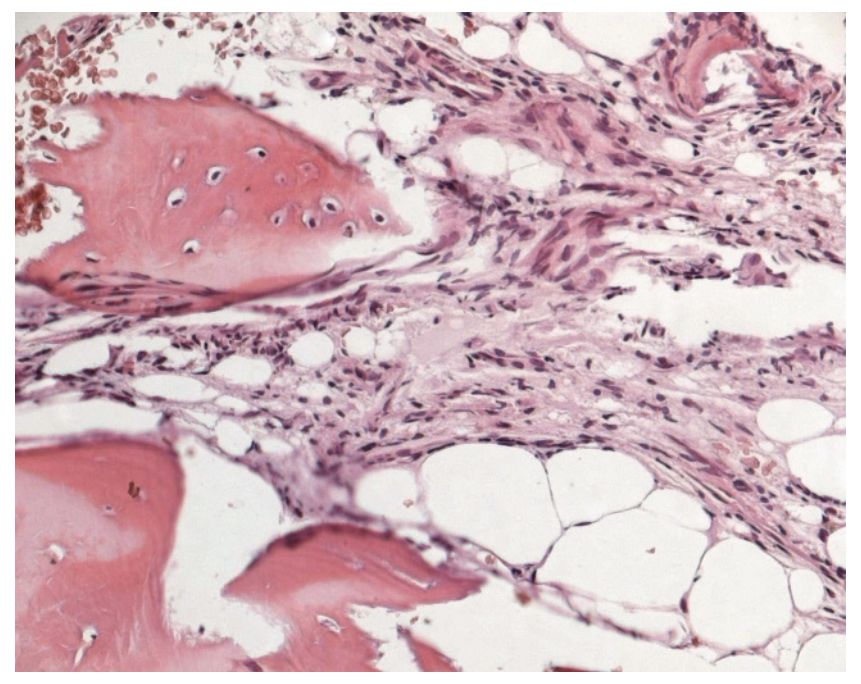

Figure 7 - Histological appearance of the material collected from the percutaneous biopsy, processed in paraffin for staining with hematoxylin and eosin. Observe the osteoid osteoma niche and the eosinophilic areas of newly formed bone without a trabecular pattern.

After the procedure, the patient was allowed to walk with the use of a Putti jacket. The jacket was used for six weeks, and the patient's pain progressively improved. One year after the procedure, computed tomography did not demonstrate any tumor, and the patient did not report any lumbar pain.

\section{DISCUSSION}

Osteoid osteoma in the vertebral column is more frequent in young adults (11-22 years) ${ }^{1}$ and is also more common in the posterior elements of the vertebra. ${ }^{10}$ The case in question did not present the typical epidemiology.

The natural history of osteoid osteoma demonstrates the possibility of spontaneous cure of the lesion after two to eight years. However, intense pain and the risk of secondary scoliosis ${ }^{20}$ justify surgical treatment in selected cases. The surgical treatment consists of en-bloc resection to remove the niche and the sclerosis halo. ${ }^{10,23,24}$

Osteoid osteoma can usually be diagnosed through computed tomography. It demonstrates a radiolucent nidus surrounded by a dense reactive rim of cortical bone which is usually less than 1 centimeter in diameter. ${ }^{25}$ However, the definitive diagnosis must be made by histopathological examination. ${ }^{22}$ Biopsy of the lesion and resection of the tumor niche aided by intraoperative computed tomography has been described by several authors. ${ }^{26-28}$

Radiofrequency ablation was initially described by Rosenthal et al. Recently, it has been successfully used in minimally invasive treatment of osteoid osteoma,,${ }^{15,29-33}$ with fewer complications compared to surgical treatment. ${ }^{15}$ However, the efficacy of this procedure still needs to be analyzed with a larger case series.

\section{REFERENCES}

1. Jaffe HL. Osteoid-osteoma. A benign osteoblastic tumor of osteoid and atypical bone. Arch Surg. 1935;31:709-28.

2. McLeod RA, Dahlin DC, Beabout JW. The spectrum of osteoblastoma. Am J Roentgenol. 1976;126:321-5.

3. Barei DP, Moreau G, Scarborough MT, Neel MD. Percutaneous radiofrequency ablation of osteoid osteoma. Clin Orthop Relat Res. 2000;373:115-24.

4. Boriani S, Weinstein JN. Differential diagnosis and surgical treatment of primary benign and malignant neoplasms. In: Frymoyer JW, editor. The adult spine. New York: Raven Press; 1997. p. 950-87.

5. Jackson RP, Reckling PW, Mants FA. Osteoid Osteoma and osteoblastoma: similar histology lesions with different natural histories. Clin Orthop Relat Res. 1977;128:303-13.

6. Lindner NJ, Ozaki T, Roedl R, Gosheger G, Winkelmann W, Wortler K. Percutaneous radiofrequency ablation in osteoid osteoma. J Bone Joint Surg Br. 2001;83:391-6.

7. Raskas DS, Graziano GP, Herzenberg JE, Heidelberger KP, Hensinger RN. Osteoid osteoma and osteoblastoma of the spine. J Spinal Disord. 1992;5:204-11.
8. Azouz EM, Korolowski K, Marton D, Sprague P, Zerhouni A, Asselah F. Osteoid osteoma and osteoblastoma of the spine in children: report of 22 cases with brief literature review. Pediatr Radiol. 1986;16:25-31.

9. Fountain EM, Burge CH. Osteoid osteoma of the cervical spine. A review and case report. J Neurosurg. 1961;18:380-3.

10. Marcove RC, Heelan RT, Huvos AG, Healey J, Lindeque BG. Osteoid osteoma: diagnosis, localization and treatment. Clin Orthop Relat Res. 1991;267:197-201.

11. Crouzet G, Mnif J, Vasdev A, Pascal-Ortiz D, Chirossel JP, Pasquier B. Osteoid osteoma of the spine: radiological aspects and value of arteriography. Four cases. J Neuroradiol. 1989;16:45-59.

12. Heiman ML, Cooley CJ, Bradford DS. Osteoid osteoma of a vertebral body: report of a case with extension across the intervertebral disk. Clin Orthop Relat Res. 1976;118:159-63.

13. Keim HA, Reine FG. Osteoid osteoma as a cause of scoliosis. J Bone Joint Surg Am. 1975;57:159-63.

14. Pettine K, Klassen R. Osteoid osteoma and osteoblastoma of the spine. J Bone Joint Surg Am. 1986;68:354-61. 
15. Rosenthal DI, Hornicek FJ, Wolfe MW, Jennings LC, Gebhardt MC, Mankin HJ. Percutaneous radiofrequency coagulation of osteoid osteoma compared with operative treatment. J Bone Joint Surg Am. 1998;80:815-21.

16. Dahlin DC. Bone tumors: general aspects and data on 6,221 cases. Philadelphia: Lippincott-Raven; 1996. p. 463

17. Mehta MH. Pain provoked scoliosis. Observations on the evolution of the deformity. Clin Orthop. 1978;135:58-65.

18. Kirwan EO, Hutton PA, Pozo JL, Ransford AO. Osteoid osteoma and benign osteoblastoma of the spine. Clinical presentation and treatment. J Bone Joint Surg Br. 1984;66:21-6.

19. Lundeen MA, Herren JA. Osteoid-osteoma of the spine: sclerosis in two levels. A case report. J Bone Joint Surg Am. 1980;62:476-8.

20. MacLellan DT, Wilson FC. Osteoid osteoma of the spine. A review of the literature of the literature and report of six new cases. J Bone Joint Surg Am. 1967;49:111-21.

21. Saifuddin A, White J, Sherazi Z, Shaikh MI, Natali C, Ransford AO. Osteoid osteoma and osteoblastoma of the spine. Factors associated with the presence of scoliosis. Spine. 1998;23:47-53.

22. Kchouk M, Mrabet A, Touibi S, Douik M, Siala M, Slimen N. Osteoid osteoma of the spine. Radiological study of 21 cases. J Radiol. 1993;74:135-42.

23. Lee D, Malawer M. Staging and treatment of primary and persistent (recurrent) osteoid osteoma: evaluation of intraoperative nuclear scanning, tetracycline fluorescence and tomography. Clin Orthop Relat Res. 1992;281:229-38.

24. Ozaki T, Liljenqvist U, Hillmann A, Halm H, Lindner N, Gosheger G, et al. Osteoid osteoma and osteoblastoma of the spine: experience with 22 patients. Clin Orthop Relat Res. 2002;397:394-402.
25. McGarry SV, Gibbs CP. Radiofrequency ablation in bone neoplasia Curr Opin Orthop. 2005;16:484-8.

26. Poey C, Clement JL, Baunin C, Assoun J, Puget-Mechinaud C, Giron J, et al. Percutaneous extraction of osteoid osteoma of the lumbar spine under CT guidance. J Comput Assist Tomogr. 1991;15:1056-8

27. Baunin C, Puget C, Assoun J, Railhac JJ, Cahuzac JP, Clement JL, et al. Percutaneous resection of osteoid osteoma under CT guidance in eight children. Pediatr Radiol. 1994;24:185-8.

28. Labbe JL, Clement JL, Dubarc B, Poey C, Raihac JJ. Percutaneous extraction of vertebral osteoid osteoma under computed tomography guidance. Eur Spine J. 1995;4:368-71.

29. Rosenthal DI, Springfield DS, Gebhardt MC, Rosenberg AE, Mankin HJ. Osteoid osteoma: percutaneous radiofrequency ablation. Radiology. 1995;197:451-4.

30. Rosenthal DI, Alexander A, Rosenberg AE, Springfield D. Ablation of osteoid osteomas with a percutaneously placed electrode: a new procedure. Radiology. 1992;183:29-33.

31. Tillotson C, Rosenberg A, Rosenthal D. Controlled thermal injury of bone: report of a percutaneous technique using radiofrequency electrode and generator. Invest Radiol. 1989;24:888-92.

32. De Berg J, Pattynama P, Obermann W, Bode PJ, Vielvoye GJ, Taminiau AH. Percutaneous computed-tomography guided thermocoagulation for osteoid osteomas. Lancet. 1995;346:350-1.

33. Mahnken AH, Tacke JA, Wildberger JE, Gunther RW. Radiofrequency ablation of osteoid osteoma: initial results with a bipolar ablation device. J Vasc Interv Radiol. 2006;17:1465-70 